\title{
Refractory Right Coronary Artery Spasm: A Case Report
}

Siamac Yazdchi ${ }^{1}$, Santosh Desai ${ }^{2}$, Janelle Rodriguez ${ }^{3}$, Meghanaprakash Hiriyur Prakash ${ }^{3}$, Ismail A. H. Bokhari $^{4,5}$

1. Internal Medicine, Banner - University Medical Center Phoenix, Phoenix, USA 2. Interventional Cardiology, Cardiovascular Associates of Mesa, Phoenix, USA 3. Cardiology, Banner - University Medical Center Phoenix, Phoenix, USA 4. Cardiology, Banner - University Medical Center Phoenix, Phoenix, USA 5. Cardiology, Kingman Regional Medical Center, St. George, USA

Corresponding author: Siamac Yazdchi, siamac.yazdchi@bannerhealth.com

\section{Abstract}

Herein, we report a case of severe coronary spasm during cardiac catheterization refractory to medical management. Although this condition is usually managed with vasodilating agents, our patient ultimately required placement of stents.

Categories: Cardiology, Internal Medicine

Keywords: coronary vasospasm, coronary stenting

\section{Introduction}

Coronary vasospasm is a common cause of myocardial infarction with no obstructive coronary atherosclerosis (MINOCA) syndrome [1]. Intra-procedural coronary spasm often resolves with the administration of vasodilators. A case of severe coronary spasm during cardiac catheterization refractory to medical management was encountered and ultimately managed by the placement of coronary stents. This case highlights an unusual management strategy for a patient with refractory coronary spasm.

Received 05/16/2019

Review began 06/09/2019 Review ended 02/06/2020 Published 02/18/2020

(c) Copyright 2020

Yazdchi et al. This is an open access article distributed under the terms of the Creative Commons Attribution License CC-BY 4.0., which permits unrestricted use, distribution, and reproduction in any medium, provided the original author and source are credited.

\section{Case Presentation}

The patient is a 52-year-old female with a past medical history of hypertension, chronic obstructive pulmonary disease, tobacco use, and polysubstance abuse. She had sustained a prior pulmonary embolism and was on anticoagulation. The patient presented with exertional angina in an outpatient setting. Her evaluation included a pharmacologic nuclear stress test which revealed anterior wall ischemia. She was referred for cardiac catheterization.

Right radial artery and right antecubital vein access were obtained for the left and right heart catheterization (LHC and RHC). Coronary angiography revealed coronary arteries without the disease (Figure 1, Video 1). After the right heart catheterization was completed, the patient started complaining of chest pain associated with ST-segment elevation in leads II and aVF on the monitor. The patient was uncomfortable and hypertensive. She was started on intravenous nitroglycerin which did not relieve her chest pain nor the STsegment elevation noted in the inferior leads. An emergent echocardiogram was performed and did not show any pericardial effusion. 


\section{Cureus}

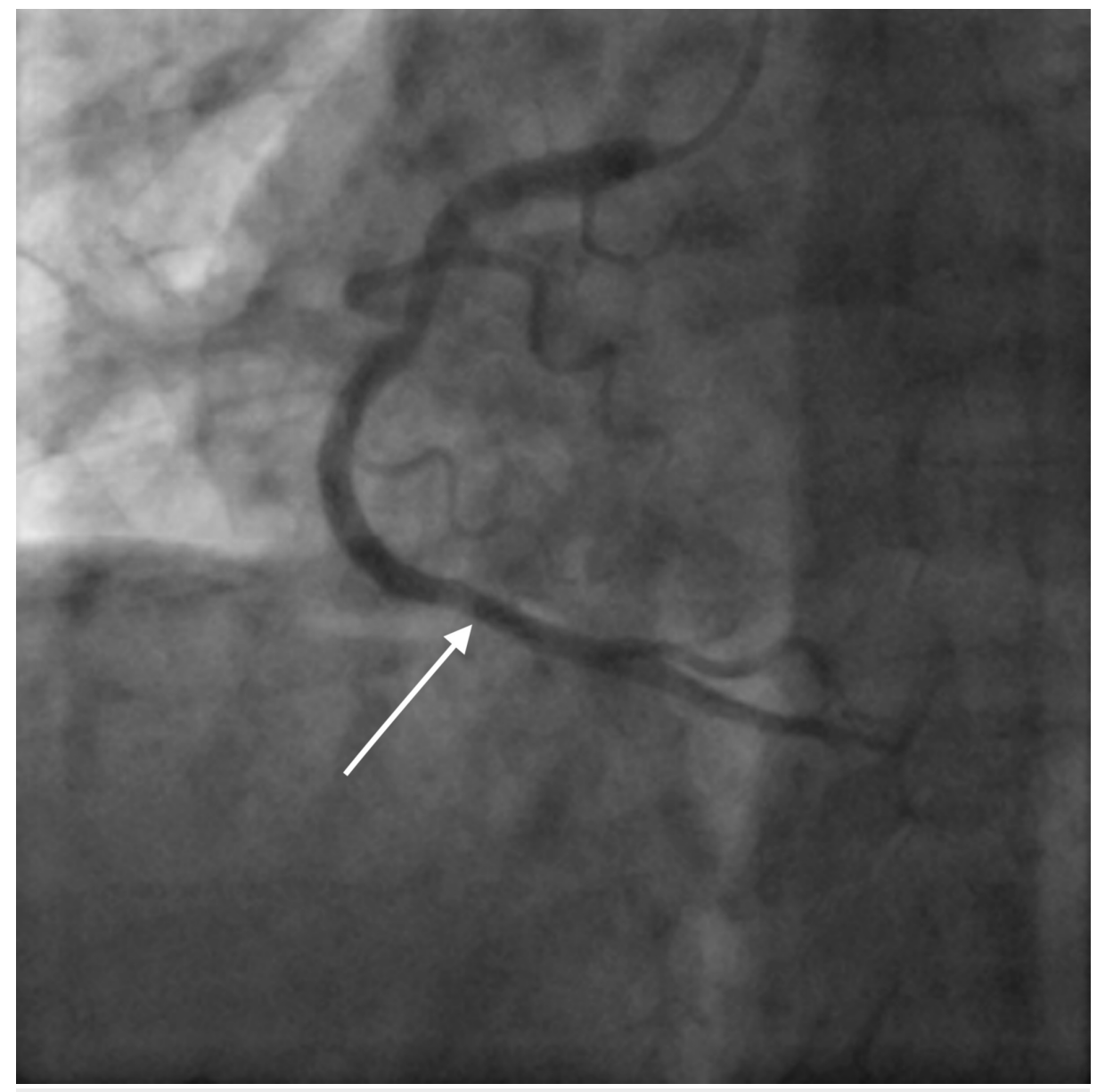

FIGURE 1: Patent right coronary artery

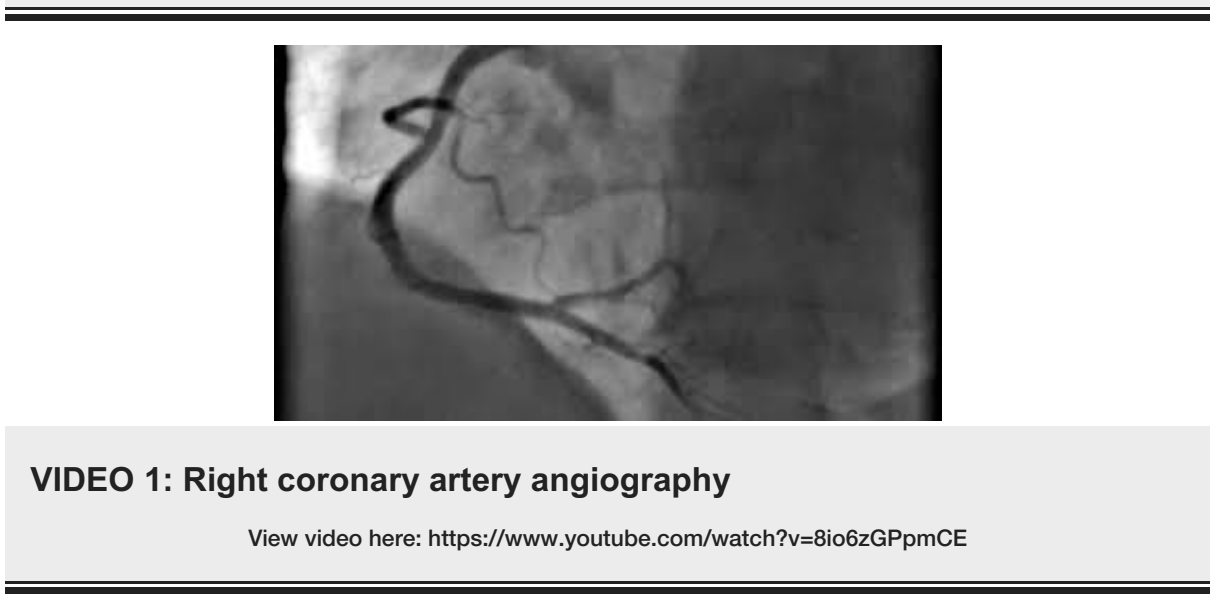

Given the persistent symptoms and ST-segment changes in the inferior leads, a decision was made to interrogate the right coronary artery again. Right coronary angiography was performed revealing severe spams from the proximal segment to the mid-vessel with no flow distally (Video 2).

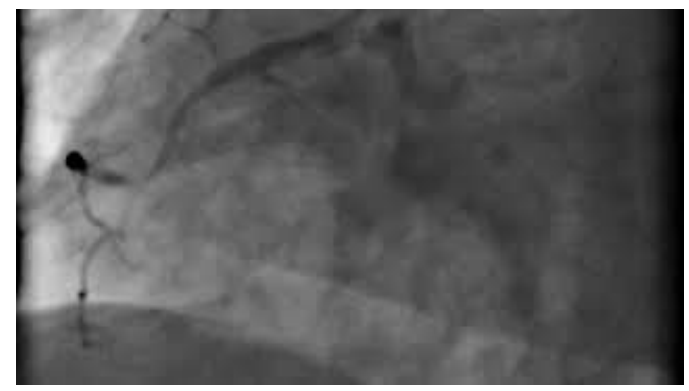


VIDEO 2: Right coronary artery spasm

View video here: https://www.youtube.com/watch?v=wICQrIFXVfc

Intracoronary nitroglycerin and nitroprusside were administered with no significant improvement. The patient was then started on nicardipine intravenously to control her blood pressure, and the decision was made to proceed with mechanical intervention. A $2.5 \mathrm{~mm}$ semi-compliant balloon was advanced into the right coronary artery and multiple inflations were performed. Intravascular ultrasound was performed revealing a $4 \mathrm{~mm}$ reference vessel size without plaque, thrombus, or dissection.

An intra-aortic balloon pump was inserted to augment diastolic coronary filling; however, the patient continued to have severe retrosternal chest pain accompanied by ST-segment elevation and continued evidence of spasm.

After waiting for several minutes, a decision was made to place coronary stents to combat the refractory spasm. The risk for myocardial necrosis from the interruption of blood flow to the distal right coronary artery (RCA) and its branches seemed greater than the risk for percutaneous coronary intervention (PCI). A $3.5 \mathrm{~mm}$ x $32 \mathrm{~mm}$ stent was placed in the distal right coronary artery, a $4 \mathrm{~mm}$ x $38 \mathrm{~mm}$ stent was placed in the middle portion of the vessel, and another $4 \mathrm{~mm} \times 32 \mathrm{~mm}$ stent was deployed to cover the proximal and distal portions of the artery (Video 3).

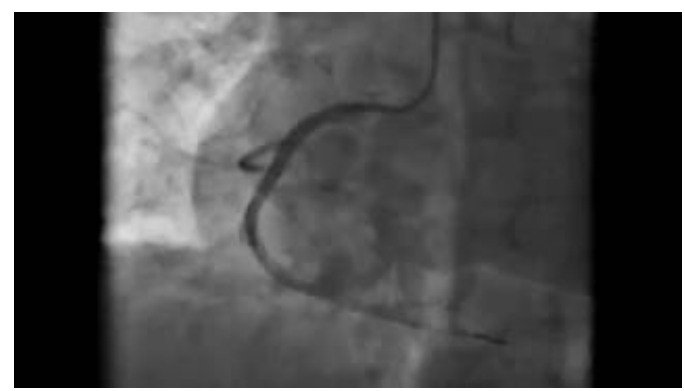

\section{VIDEO 3: Right coronary artery post-percutaneous coronary intervention}

View video here: https://www.youtube.com/watch?v=x-ELObmz-s8

The patient's symptoms resolved quickly after stenting. She was monitored closely in the Intensive Care Unit. She made an uneventful recovery and was discharged home.

\section{Discussion}

Coronary spasm was first demonstrated by Gensini in 1962 [2]. Changes in autonomic activity, as well as the use of illicit drugs (such as cocaine and amphetamines), have been identified as possible culprits. Guidewire or balloon manipulation at the time of percutaneous coronary intervention are among the most common causes of this condition today [3-5].

The mechanisms for catheter-induced spasm are not completely understood, but anatomic characteristics and myogenic reflexes caused by mechanical stimulation of the RCA may be involved [6]. The main treatment for this condition is a combination of calcium antagonists [7]. The use of beta-blockers is traditionally avoided, given their potentially detrimental effect of limiting beta-receptor-mediated dilatation and promoting unopposed alpha-adrenergic coronary vasoconstriction [8]. Donatelli et al. described a case of coronary artery spasm six hours after coronary bypass grafting, which was successfully managed with an intracoronary infusion of isosorbide dinitrate and intravenous nifedipine [9].

PCI is not routinely indicated for patients with focal spasm and minimal coronary disease. However, PCI may be helpful if a significant coronary obstruction is thought to be a potential trigger for focal spasm. Stent placement may be an effective therapy for patients with medically refractory vasospasm associated with mild to moderate coronary disease [10-11].

\section{Conclusions}

The unique and interesting features of this case report making it worthy of consideration are 1) the refractoriness of the spasm to medical therapy with vasodilators, 2) the distance of the spasm from the catheter manipulation at the ostium of the RCA, and 3) the intravenous ultrasound findings of no atherosclerosis in the RCA, a finding that is different from other cases of variant angina encountered in the 
literature. To our knowledge, this is a unique case of coronary spasm with normal coronaries intractable to medical therapy treated with stents.

\section{Additional Information \\ Disclosures}

Human subjects: Consent was obtained by all participants in this study. Conflicts of interest: In compliance with the ICMJE uniform disclosure form, all authors declare the following: Payment/services info: All authors have declared that no financial support was received from any organization for the submitted work. Financial relationships: All authors have declared that they have no financial relationships at present or within the previous three years with any organizations that might have an interest in the submitted work. Other relationships: All authors have declared that there are no other relationships or activities that could appear to have influenced the submitted work.

\section{Acknowledgements}

We would like to thank Ashish Pershad, M.D., Program Director, Interventional Fellowship Program Cavanagh Heart Center at Banner University Medical Center Phoenix, AZ for his mentorship and also reviewing coronary images.

\section{References}

1. Niccoli G, Scalone G, Crea F: Acute myocardial infarction with no obstructive coronary atherosclerosis: mechanisms and management. Eur Heart J. 2015, 36:475-81. 10.1093/eurheartj/ehu469

2. Gensini SS, Di Giorgi S, Murad-Netto S, Black A, Kelly AE: Arteriographic demonstration of coronary artery spasm and its release after the use of a vasodilator in a case of angina pectoris and in the experimental animal. Angiology. 1962, 13:550-53. 10.1177/000331976201301202

3. Lanza GA, Pedrotti P, Pasceri V, Lucente M, Crea F, Maseri A: Autonomic changes associated with spontaneous coronary spasm in patients with variant angina. J Am Coll Cardiol. 1996, 28:1249-56. 10.1016/S0735-1097(96)00309-9

4. Stern S, Bayes de Luna A: Coronary artery spasm: a 2009 update. Circulation. 2009, 119:2531-34. 10.1161/CIRCULATIONAHA.108.843474

5. Lange RA, Cigarroa RG, Yancy CW Jr, et al.: Cocaine-induced coronary-artery vasoconstriction. N Engl J Med. 1989, 321:1557-62. 10.1056/NEJM198912073212301

6. Sueda S, Fujimoto K, Sasaki Y, Sakaue T, Habara H, Kohno H: Catheter-induced spasm in the proximal right coronary artery. Intern Med. 2019, 58:21-30. 10.2169/internalmedicine.1483-18

7. Xu R, Cheng C, He F, Liu X, Liao Q, Ji J : Two cases of non-intervention-related vascular intense spasm following stent implantation in the coronary artery. Exp Ther Med. 2013, 5:1623-26. 10.3892/etm.2013.1027

8. Kalsner S: Coronary artery spasm. Multiple causes and multiple roles in heart disease . Biochem Pharmacol. 1995, 49:859-71. 10.1016/0006-2952(94)00447-T

9. Donatelli F, Mariani MA, Pocar M, Triggiani M, Pelenghi S, Grossi A: Successful treatment of coronary artery spasm following coronary artery bypass grafting. Cardiologoa. 1993, 38:601-605.

10. Corcos T, David PR, Bourassa MG, Val PG, Robert J, Mata LA, Waters DD: Percutaneous transluminal coronary angioplasty for the treatment of variant angina. J Am Coll Cardiol. 1985, 5:1046-54. 10.1016/S0735-1097(85)80004-8

11. Gaspardone A, Tomai F, Versaci F, et al.: Coronary artery stent placement in patent with variant angina refractory to medical treatment. Am J Cardiol. 1999, 84:96-98. 10.1016/S0002-9149(99)00201-5 